\title{
The influence of surface tension on wetting in dampening solution and sustainability of printing: A review
}

\author{
ABSTRACT \\ Offset is defined as a printing technique using a system of two-flu- \\ ids (ink + dampening solution) that requires a constant monitoring \\ and a balancing system due to the physical-chemical features of the \\ process. Ink and dampening solution on the printing plate surface \\ should not be intergraded during the chemical interaction. Image and \\ non-image areas on the plate surface can be separated from each oth- \\ er only through the interaction of dampening solution and ink. \\ The dampening solution is responsible for the wetting of non-image \\ areas on a printing plate, and are applied to the entire plate. In the wet- \\ ting process, the amount of the dampening solution on the plate should \\ be at the lowest level. This can be provided only by lowering the sur- \\ face tension of the dampening solution. Thus, quality printing results, \\ such as edge sharpness, high color intensity and high print gloss are \\ achieved with a small amount of wetting on the printing plate surface. \\ In this study, the wetting of the printing plate surface is investi- \\ gated under the effects of surface tension of dampening solu- \\ tion and its angle of contact with the printing plate and current \\ studies related to the subject are reviewed and discussed.
}

\author{
Cem Aydemir \\ Semiha Yenidoğan (D) \\ Marmara University, \\ School of Applied Sciences, \\ Department of Printing \\ Technologies, Istanbul, Turkey \\ Corresponding author: \\ Cem Aydemir \\ e-mail: \\ cemaydemir@marmara.edu.tr
}

First recieved: 06.12.2018. Accepted: 06.03.2019.

\section{KEY WORDS}

Dampening solution, surface tension, contact angle, wetting, isopropyl alcohol-free

\section{Introduction}

The "wet" offset printing process is a "two-fluid" system (ink + dampening solution) that requires constant monitoring and balancing system. (Rossitza, 2015).

One of many elements that influence print quality in offset is the wetting process of nonprinting areas of the printing plate (Cigula et al., 2010). On the offset printing plate surface, the sections that are required and not required to convey ink are at the same level. Due to the fact that that there is no height difference, the areas on the plate surface which are demanded to be inked and not inked can be separated with the interaction between dampening solution and printing ink
(Aydemir \& Özakhun, 2014). Non-imaging areas of the printing plate are formed by aluminum mostly surface treated to enhance their wettability (Huber, 2008). In the areas on the printing plate surface that are demanded to be printed there is an emulsion material, and in the areas that are not demanded to be printed, there are micro grain pores that water can be adsorbed. The imaging areas with emulsion on the plate surface have an oleophilic feature to receive ink and non-imaging grained areas have a hydrophilic feature to receive moisturizing water (Novaković, Karlović \& Gojo, 2009).

Dampening solution is a water-based mixture specially formulated to dampen lithographic printing plates before they are contacted by the inking rollers (Arohit, Singh 
\& Ravinder, 2018). These solutions keep the non-image areas of a plate moistened so that they will not accept ink, and are applied to the entire plate. During the chemical interaction on the printing plate, the dampening solution and ink are not immiscible. Its possibility of wetting the printing plate is highly dependent on the concentration of the prepared dampening solution and it is a key factor in obtaining high quality prints (contrast between solid print areas and half tones, gloss, etc.) (Krüss, 1999).

The water present in nature includes variable amounts of dissolved or suspended extraneous matter. These can be inorganic (alkali chloride, sulfates, calcium and magnesium compounds etc.) or organic solid, liquid substances and dissolved gases. For the creation of a homogenous and continuous water film layer that is required in the offset printing process, dampening solution should have certain characteristics. The properties of tap water that has an impact on dampening solution is very important in terms of printing quality and its direct use in printing may cause negativities. It is not possible to make continuous damping with tap water and obtain ideal printing results. The data on the appropriateness of water for printing is provided by the hardness, $\mathrm{pH}$, surface tension, temperature and conductivity parameters that differentiate between geological regions (Heidelberger Druckmaschinen AG, 2009). Therefore, in order to use tap water as a dampening solution in offset printing, these characteristics should be measured periodically and transformed into process water by additive supplements (Snoeijer \& Andreotti, 2008).

The surface tension of the dampening solution is a feature that has to be considered for the sustainability of printing quality in offset. The present study assessed the impacts of the surface tension of the dampening solution on the wetting of the printing plate, alcohol and alcohol substitutes, which are components of the dampening solution, in terms of environmental impacts.

\section{Dampening solution additives}

The dampening solution is a water-based mixture formulated to dampen the lithographic printing plates before interacting with the ink rollers. (Thibault, 2008). Additives should be added to improve the physical and chemical properties of this water-based dampening solu- tion (Cigula, Poljaiek \& Gojo, 2009). As a result of various studies and experiments on printing, it was determined that the ideal dampening and quality printing results were obtained with dampening solution in the range of pH 4.8- 5.5 values (Table 1). Because the surface tension of water between these values is more acceptable levels.

\section{In the case that dampening water is too acidic $(\mathrm{pH}<4,8)$}

- The acid reacts with aluminum and deforms the printing plate surface. The hills of grain pores are eroded and so that the printing plate cannot hold dampening water.

- The emulsion structure (especially in small size dot areas) in the image areas weakens, size of the dot does change.

- Dryers in the ink (lead, mangan, cobalt etc.) react with the acid and the oxidation polymerization drying of wet ink film is delayed.

- The acid reacts with the coating of the paper and the surface structure of the paper is deteriorated

In the case that dampening water is alkaline $(\mathrm{pH}>5,5)$

- Oils in ink dissolve in water which has alkaline form and saponification occurs.

- The limit surface tension decrease between water and ink. Thus, ink and water are partially miscible. In other words, a stable emulsion (chemical balance) cannot be established. In this case, the color intensity of the ink decreases considerably.

- The non-image areas of the printing plate are oiled and partially receive ink.

- On the surface of the plate takes ink in the non-image areas.

- More dampening water is needed to wet the printing plate.

- Ink transfer declines.

- Drying of ink becomes difficult.

- The edge sharpness of dots and lines is reduced.

Dampening or fountain solution additives are mixtures used in the preparation of dampening solution to improve adequate emulsification and wetting. Additive materials are important in terms of $\mathrm{pH}$ adjustment and stabilization of the dampening solution (Deshpande, 2011). In order to maintain tap water at its ideal pH

\section{Table 1}

$\mathrm{H}+$ and $\mathrm{OH}$ - ion amount and $\mathrm{pH}$ value (Aydemir \& Özakhun, 2014)

\begin{tabular}{|c|c|c|c|c|c|c|c|c|c|c|c|c|c|c|c|}
\hline \multirow[b]{3}{*}{ pH-value } & \multicolumn{7}{|c|}{ Acidic } & \multirow{3}{*}{$\begin{array}{c}\text { Neutral } \\
7\end{array}$} & \multicolumn{7}{|c|}{ Basic } \\
\hline & \multicolumn{4}{|c|}{ Strong } & \multicolumn{3}{|c|}{ Weak } & & \multicolumn{3}{|c|}{ Weak } & \multicolumn{4}{|c|}{ Strong } \\
\hline & 0 & 1 & 2 & 3 & 4 & 5 & 6 & & 8 & 9 & 10 & 11 & 12 & 13 & 14 \\
\hline $\mathrm{H}+$ & $10^{\circ}$ & $10^{-1}$ & $10^{-2}$ & $10^{-3}$ & $10^{-4}$ & $10^{-5}$ & $10^{-6}$ & $10^{-7}$ & $10^{-8}$ & $10^{-9}$ & $10^{-10}$ & $10^{-11}$ & $10^{-12}$ & $10^{-13}$ & $10^{-14}$ \\
\hline OH- & $10^{-14}$ & $10^{-13}$ & $10^{-12}$ & $10^{-11}$ & $10^{-10}$ & $10^{-9}$ & $10^{-8}$ & $10^{-7}$ & $10^{-6}$ & $10^{-5}$ & $10^{-4}$ & $10^{-3}$ & $10^{-2}$ & $10^{-1}$ & $10^{\circ}$ \\
\hline
\end{tabular}


values ( $\mathrm{pH} 4,8-5,5)$, they are added into dampening solution before printing (Yuan \& Lee, 2013).

Generally, the additives are concentrated solutions which should be diluted with water. Most one-step concentrates contain a synthetic or natural gum, an alcohol substitute, acetic acid, phosphoric acid, glycerin, and other major essential ingredients, and simply require being diluted with water. On the other hand, two-step concentrates mostly comprise all of the above-mentioned ingredients, with the exception of the alcohol substitute, and alcohol substitute is included in the second-step (Thibault, 2008; Yuan \& Lee, 2013).

The ability of the dampening solution to produce a homogenous wetting on the non-image areas of the offset printing plate is an important factor for the quality of the printing process. The wetting agents in the additive reduce the surface tension value of the dampening solution to below tap water. In this way, the forces that resist the spread of the water on the printing plate surface are reduced and the continuous and fine damp film is stabilized on the plate. This makes it possible to reduce the flow of dampening solution and obtain a thin and stable water/ink emulsion, ideal point value, high printing gloss and optimized solid tone/ halftone printing contrast (Oros, 2012). In addition, bacterial growth and oxidation of the channels of the printing machine are prevented by means of the biocides and corrosion inhibitors present in its content.

\section{Surface Tension and Wetting of Dampening Solution}

On the printing plate, the areas to be printed accept the ink film and the not to be printed areas have a hydrophilic structure that accepts the damp film. The areas that are demanded to be printed and not to be printed on plate are separated from each other through an interaction between water and ink. In order to make this separation in a clear way, the angle of contact that dampening solution makes with the plate surface should have the lowest value that enables required dampening to be provided. Low contact angle always provides a better dampening (Aydemir \& Özakhun, 2014). The contact angle is determined by a combination of surface tension and external forces (usually gravity). Theoretically, the contact angle is expected to be characteristic for a given solid-liquid system in a specific environment (Kiurski \& Oros, 2012). In general, wettability studies consider the measurement of contact angles as the primary data which demonstrate the degree of wetting in the case of an interaction between a solid and liquid (Aydemir et al., 2017). Tensions between the existed surfaces determine whether a droplet will be diffused to a solid surface or it will be wetting or not wetting the surface. (Aurenty, Lemery \& Gandini, 1997).

In order to initiate the wetting process, a liquid is contacted with a solid surface, and two molecular species are brought together by intermolecular interactions. The wetting and solid wettability is usually illustrated with a small liquid droplet resting on a flat horizontal solid surface, from which the angle at the three phases in contact can be determined. (Sappi, 2004). When a drop of water is dripped onto a solid surface, this drop on the solid surface (the liquid phase), the with how well it wetting the solid, the contact angle becomes so small (Figure 1) (Aydemir \& Özakhun, 2014).

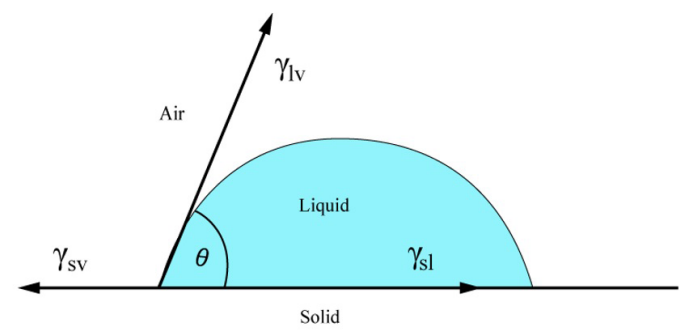

» Figure 1: Contact angle and the three-phase-contact line (Aydemir \& Özakhun, 2014)

The shape of the droplet is determined by the Young's relation (Eq. 1), which is satisfied at equilibrium,

Young's equation,

$$
\begin{gathered}
\gamma_{s v}=\gamma_{s l}+\gamma_{l v} \times \cos \cos \theta \\
\cos \cos \theta=\frac{\gamma_{s v}-\gamma_{s l}}{\gamma_{l v}}
\end{gathered}
$$

where the subscripts relate to:

$V_{\text {sv }}=$ solid/vapour area
$V_{\mathrm{sl}}=$ solid/liquid area
$V_{\mathrm{IV}}=$ liquid/vapour area

From the equation, it can be drawn a conclusion that liquid/air and solid/liquid phase limit surface tensions should be reduced for enabling liquid to have a contact angle which is below $90^{\circ}$. Reduction of the surface tension of the liquid is provided by surface active agents which reduce surface tension between phases and also called as wetting agents.

The increase in surface tension of the water causes the contact angle that it makes with the printing plate surface to increase. Small contact angles $\left(<<90^{\circ}\right)$ correspond to high wettability, while large contact angles $\left(>>90^{\circ}\right)$ correspond to low wettability (Aurenty, Lemery $\&$ Gandini, 1997). When the contact angle is higher than $90^{\circ}$, the wetting of solid surface printing plate by liquid becomes inadequate. On the contrary, when this angle decreases, wetting enhances (Figure 2). 

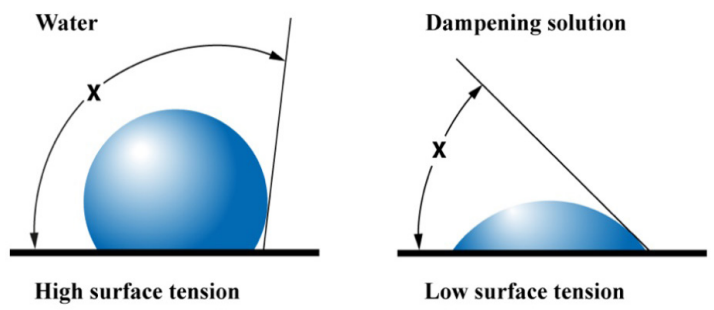

» Figure 2: Contact angle and dampening

(Aydemir \& Özakhun, 2014)

As the contact surface tension decreases, the force that resists to the diffusion of dampening solution to the plate surface also decreases, and a homogeneous and thin damp film is stabilized on the printing plate. In this way, quality printing results such as halftone dot edge sharpness and high color intensity can be obtained with a small amount of dampening solution. When the contact surface tension increases, the force that resists to the diffusion of dampening solution to the plate surface also increase; for this reason, a balance is tried to be set by giving a more dampening solution to the system.

In this case, the following problems occur:

- The color intensity decreases with the droplets of dampening solution adsorbed onto the ink surface. More gray and faded print results are obtained.

- As the amount of ink must also be increased to adjust the chemical balance (ink/water balance) on the printing plate surface, the problems of dot gain in the printing also increases.

- The use of excess dampening solution to wetting the surface of the printing plate causes pilling and chemical structure changes in the ink.

- Using a redundant amount of dampening solution causes a change in the dimensional stability (fan-in, fan-out) of the paper.

- Drying of ink becomes more difficult.

The interaction concerning dampening solution is that the surface tension of water at $72 \mathrm{mN} / \mathrm{m}$ is lowered to be about range of 20 to $22 \mathrm{mN} / \mathrm{m}$ due to the addition of alcohol or substitute, (Figure 3) (Deshpande, 2011).

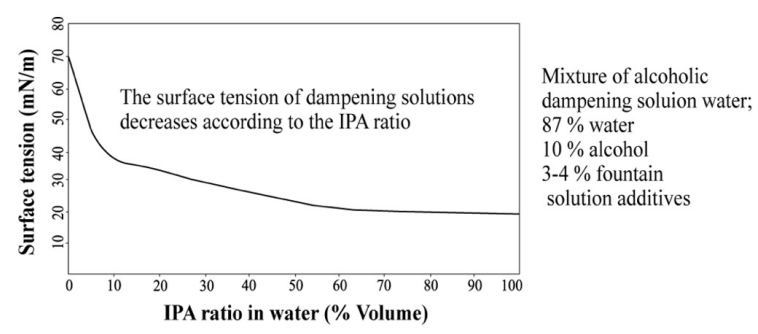

» Figure 3: The change of the upper surface tension of water with alcohol addition

\section{Alcohol, Alcohol-Reduced and Alcohol-Free Dampening Solution}

In offset, with the acceleration of the printing machine, the dampening solution film on the plate gradually lose its balance, and its molecular structure starts to be fractured. With the purpose of eliminating these problems, 5-8\% isopropyl alcohol (IPA) or pure alcohol (ethyl alcohol) is added to the dampening solution together with additives (Table 2). Alcohol is a hydrophilic wetting agent which is used to reduce the surface tension of the dampening solution and to protect the without ink areas on the printing plate. Generally, IPA in offset printing, reducing the surface tension of dampening solution it ensures better wetting and adhesion on the surface of printing plates, and stabilizes the ink-water balance (Rossitza, 2015).

\section{Table 2}

Surface tensions of certain liquids (Accu Dyne Test, 2018)

\begin{tabular}{l|c|c|c|c|c|c|c}
\hline $\begin{array}{l}\text { Liquid } \\
\text { Name }\end{array}$ & $\begin{array}{c}\text { Mol. } \\
\text { Formula }\end{array}$ & $\begin{array}{c}\text { CAS } \\
\text { Number }\end{array}$ & $\begin{array}{c}\text { Mol. } \\
\text { Wt. }\end{array}$ & $\begin{array}{c}\text { Surface } \\
\text { Tension }\end{array}$ & $\begin{array}{r}\text { Specific } \\
\text { Density }\end{array}$ & \multicolumn{2}{|c|}{ Viscosity } \\
CP & cs \\
\hline Water & $\mathrm{H}_{2} \mathrm{O}$ & $7732-18-5$ & 18.02 & $72.8 \mathrm{mN} / \mathrm{m}$ & 0.999 & 0.89 & 0.89 \\
\hline $\begin{array}{l}\text { Ethylene } \\
\text { glycol }\end{array}$ & $\mathrm{C}_{2} \mathrm{H}_{6} \mathrm{O}_{2}$ & $107-21-1$ & 62.07 & $48 \mathrm{mN} / \mathrm{m}$ & 1.111 & 16.1 & 14.5 \\
\hline $\begin{array}{l}\text { Propanol } \\
\text { (isopropyl } \\
\text { alcohol) }\end{array}$ & $\mathrm{C}_{3} \mathrm{H}_{8} \mathrm{O}$ & $67-63-0$ & 60.10 & $23.3 \mathrm{mN} / \mathrm{m}$ & 0.783 & 2.04 & 2.61 \\
\hline $\begin{array}{l}\text { Ethanol } \\
\text { (ethyl } \\
\text { alcohol) }\end{array}$ & $\mathrm{C}_{2} \mathrm{H}_{6} \mathrm{O}$ & $64-17-5$ & 46.07 & $22.0 \mathrm{mN} / \mathrm{m}$ & 0.787 & 1.07 & 1.36 \\
\hline
\end{tabular}

With Isopropyl alcohol soluble in water and eter, surfactants in additives, reduces the static and dynamic surface tension of the dampening water. In this way, the diffusion impact of water increases and better wetting and adsorption on the printing plate surface can be provided (Rossitza, 2015).

IPA might have negative impacts on human health in the case of high concentrations. The higher the IPA concentration in the dampening solution is the higher the evaporation rate of the process. Hence a rise in IPA consumption causes evaporation and accordingly IPA concentration in the pressroom to increase at disproportionately high rates. Majority of the industrialized countries have determined maximum occupational exposure limits (OELs) for IPA. The average concentration values measured in the production process must be between 200 and 400 ppm (parts per million = milliliters per cubic meter), depending on the country (Heidelberger Druckmaschinen AG, 2011). In recent years the use of IPA has been reduced, and in many cases eliminated, by using substitutes (Tåg, 2013). Reducing the use of IPA has many 
advantages. This can be given briefly as; Reducing the use of IPA in the dampening solution has many advantages.

These advantages can be listed as follows:

- Improvement in occupational health and safety

- Lower odor levels in the pressroom

- Increased safety

- Access to environmental incentives and subsidies (country-specific)

- Costs reduction potential

- Conservation of the environment

- Improves the environmental sensitivity of the company

- Enhancing in the of customers environmental awareness

- Improves the print shop's image with environmentally aware customers

- Improves the image of the company's environmental sensitivity.

IPA-free dampening solution contain alcohol substitutes, instead of isopropyl alcohol (Rossitza, 2015; Aydemir \& Özakhun, 2014). There is a number of studies that have been conducted on the use of non-ionic surfactants as an alternative to IPA. The reason is due to the Volatile Organic Compound (VOC) emissions attributed to the evaporation of isopropyl alcohol and the level of environmental regulation this lead to (Tåg, 2013). Isopropyl alcohol, like almost all volatile organic compounds (VOC), contributes to summer smog. In addition, the VOCs also contributes to global warming by this means escalate the greenhouse impact (Heidelberger Druckmaschinen AG, 2011).

There is now consumer pressure to use renewable rather than petroleum-based resources (Aydemir et al., 2018). With alcohol substitutes, the risk of flammability and explosion can be minimized. In this way, the safety risks, and negative impacts on health and ecology that arise from the alcohol used in the offset printing process can be prevented (Snoeijer \& Andreotti, 2008).

\section{Conclusion}

The following conclusions can be presented about the impact of the surface tension of the dampening solution on printing plate wettability.

- Due to the fact that alcohol and alcohol substitutes decrease the static and dynamic surface tension of dampening solutions, with a smaller amount of dampening solution on the printing plate, diffusion and wetting on a wider area can be provided (Figure 3).

-When alcohol and alcohol substitutes are compared to each other, IPA free based damp- ening solution expresses slightly faster wetting at short time scales but the IPA based dampening solution reaches saturation faster at longer time scales (Tåg, 2013).

- In terms of printability, less use of dampening water by reducing surface tension enables to obtain an ideal dot gain, a edge sharpness of dots and lines, saturating back ground and print gloss in colors.

- Using less dampening solution reduces the amount of ink that is necessary for the chemical balance that will be set on the printing plate surface. Thus, the drying period of the thinner ink film on the substrate surface is shortened, the adhesion and contamination problems are reduced. Finishing processes can be started in a shorter time.

-When the ink is assessed from the perspective of rheology; reducing the surface tension and less use of dampening water do not affect the viscosity and adhesion properties.

- IPA is responsible for certain functions in offset printing. It reduces the surface tension of the dampening solution, ensures more effective wetting of the water rollers and printing plate, and stabilizes the ink-water balance. However, using IPA in dampening solution has a negative impact on the environment and on the climate in the pressroom and thus also on employee health. This situation should not be overlooked. (Heidelberger Druckmaschinen AG, 2011).

By considering the given situations, it can be said that in order to provide better wetting on the offset printing plate surface, the surface tension of the dampening solution should be kept under control. When health and environmental impacts are considered; alcohol-reduced or alcohol-free dampening solution should be preferred for reducing the negative impacts of alcohol in offset printing.

\section{References}

Accu Dyne Test. (2018) Viscosity, Surface Tension, Specific Density and Molecular Weight of Selected Liquids. Available from: https://www.accudynetest.com/visc_table.html?sortby=sort_surface_tension [Accessed: 27th November 2018]. Arohit, G., Singh, N. \& Ravinder (2018) Observing various aspects of eco friendly dampening solution (unitrol). International Journal of Engineering Sciences \& Research Technology. 7 (2), 125-127. Available from: doi: 10.5281/zenodo.1165714 [Accessed 10th September 2018].

Aurenty, P., Lemery, S. \& Gandini, A. (1997) Dynamic spreading of fountain solution onto lithographic anodized aluminium oxide. Printing Industries of America. 563-576. Available from: https://www. print- 
ing.org/taga-abstracts/dynamic-spreading-of-fountain-solution-onto-lithographic-anodized-aluminum-oxide/ [Accessed: 17th November 2018].

Aydemir, C. \& Özakhun, C. (2014) Matbaa Malzeme Bilimi. Istanbul, Marmara University Publishing.

Aydemir, C., Yenidoğan, S., Karademir, A. \& Kandirmaz, E.A. (2018) The examination of vegetable-and mineral oil-based inks' effects on print quality: Green printing effects with different oils. Journal of Applied Biomaterials \& Functional Materials.16 (3), 137-143. Available from: doi: 10.1177/2280800018764761 [Accessed: 20th November 2018].

Aydemir, C., Yenidoğan, S., Karademir, A. \& Arman, E. (2017) Effects of color mixing components on offset ink and printing process. Materials and Manufacturing Processes. 32 (11), 1310-1315. Available from: doi: 10.1080/10426914.2017.1279323 [Accessed: 19th November 2018].

Cigula, T., Gojo, M., Novaković, D. \& Pavlović, Z. (2010) Influence of various concentrates on quality of printing plates' wetting process. Machine Design. 2 (1), 325-330. Available from: https://www.academia.edu/27589657/Influence_of_Various_Concentrates_on_Quality_of_Printing_Plates_Wetting_Process/ [Accessed 11th October 2018].

Cigula, T., Poljaiek, S.M. \& Gojo, M. (2009) Defining the properties of fountain solution depending on type of surface active substance, International conference MATRIB 2009, 24-26 June 2009, Vela Luka, Croatia. Zagreb, Croatian Society for Materials and Tribology. pp. 16-20.

Deshpande, S. S. (2011) Fountain solution in lithographic offset printing. Journal of Engineering Research and Studies. 2 (2), 82-88. Available from: https://www.technicaljournalsonline.com/ jers/VOL\%2OII/JERS\%2OVOL\%2OII\%2OISSUE\%20 II\%2OAPRIL\%2OJUNE\%202011/ARTICLE\%2018\%20 JERS\%2OVOL\%2OII\%2OISSUE\%2OII\%2OAPRIL-\%20 JUNE\%202011.pdf [Accessed: 5th November 2018].

Heidelberger Druckmaschinen AG (2009) Dampening solutions in offset printing. Heidelberg, Print Media Academy. Available from: http:// www.monochrom.gr/UserFiles/profi_tip_1. pdf [Accessed: 9th October 2018].

Heidelberger Druckmaschinen AG (2011) Alcohol-Free and Alcohol-Reduced Printing. Heidelberg, Print Media Academy. Available from: https://www.heidelberg.com/global/media/en/ global_media/company__about_us/eco_publications/alcohol_free_and_alcohol_reduced_printing.pdf [Accessed: 22th November 2018].

Huber Group (2008) Fountain Solution in Offset Printing. Kirchheim, MHM Holding GmbH. Available from: http://www. hubergroup.net/pdffiles/inkformarion/INKFORMATION_2_en_08. pdf [Accessed: 4th September 2018].

Kiurski, J. \& Oros, I. (2012) The influence of pH/ conductivity of fountain solution on dot cir- cularity, line and text raggedness. Journal of Graphic Engineering and Design. 3 (2), 1-7.

Krüss GmbH (1999) Fountain Solutions for Offset Printing. Hamburg, Krüss GmbH. Available from: https://www.kruss-scientific.com/fileadmin/ user_upload/website/literature/kruss-ar212-en. pdf [Accessed: 18th October 2018].

Novaković, D., Karlović, I., \& Gojo, M. (2009) Influence of the surface characteristics on quality of the offset printing plate. International conference MATRIB 2009, 24-26 June 2009, Vela Luka, Croatia. Zagreb, Croatian Society for Materials and Tribology. pp. 142-148.

Oros, I. (2012) The influence of physico-chemical parameters of fountain solution on print quality. International Journal of Modern Engineering Research. 2 (5), 3585-3593. Available from: http://www.ijmer.com/papers/Vol2_Issue5/ CY2535853593.pdf [Accessed: 3th November 2018].

Rossitza, S. (2015) Offset printing without isopropyl alcohol in damping solution. Energy Procedia. 74, 690-698. Available from: doi: 10.1016/j. egypro.2015.07.804 [Accessed 15th October 2018]

Sappi Fine Paper Europe (2004) Paper, Ink and Press Chemistry. Brussels, Sappi. Available from: http:// www.monochrom.gr/UserFiles/sappi_ink_Fountain.PDF [Accessed 5th October 2018].

Snoeijer, J.H. \& Andreotti, B. (2008) A microscopic view on contact angle selection. Physics of Fluids. 20 (5), 1-11. Available from: doi: 10.1063/1.2913675 [Accessed: 9th October 2018].

Tåg, C.M. (2013) Liquid Transportation and Distribution During (Re) Wetting: Impact on Coated Papers in Printing. PhD thesis. Åbo Akademi University Finland.

Thibault, L. A. (2008) Fountain solution chemistry. Available from: https://graphicartsmag. com/articles/2008/07/fountain-solution-chemistry/ [Accessed: 12th November 2018].

Yuan, Y. \& Lee, T.R. (2013) Contact Angle and Wetting Properties. In: Bracco, G. \& Holst, B. (eds.) Surface Science Techniques. Springer Series, Volume 51, Berlin, Springer Berlin Heidelberg, pp. 3-34. Available from: doi: 10.1007/978-3-64234243-1_1 [Accessed: 15th November 2018]. 


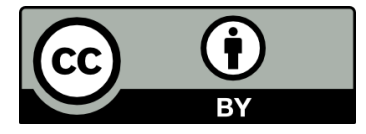

(c) 2019 Authors. Published by the University of Novi Sad, Faculty of Technical Sciences, Department of Graphic Engineering and Design. This article is an open access article distributed under the terms and conditions of the Creative Commons Attribution license 3.0 Serbia (http://creativecommons.org/licenses/by/3.0/rs/). 